\title{
Reincidências do trágico na poesia de Sophia de Mello Breyner Andresen
}

\section{Carlos Roberto dos Santos Menezes ${ }^{1}$}

Resumo: Sophia de Mello Breyner Andresen possui afinidade com a Grécia e os temas da Cultura Clássica. Dentre as múltiplas faces que a sua poesia apresenta relacionada a este tema, a tragédia grega aparece como uma presença fantasmática que evidencia um drama na sua escrita, demonstrando a presença harmônica da reversibilidade dos contrários presente desde o seu primeiro poema de Poesias, passando pelas figuras de Apolo e Dionísio, até chegar nos versos sobre o salazarismo e a Revolução dos Cravos. Sendo assim, o presente artigo busca averiguar as reincidências do trágico na escrita andresiana.

Palavras-chave: Sophia de Mello Breyner Andresen, Tragédia Grega, Apolo, Dionísio, Poesia portuguesa contemporânea.

\section{RECURRENCES OF THE TRAGIC IN THE POETRY OF SOPHIA DE MELLO BREYNER ANDRESEN}

\begin{abstract}
Sophia de Mello Breyner Andresen has affinity for Greece and the themes of Classical Culture. Among the many faces that his poetry presents related to this theme, the Greek tragedy appears as a ghostly presence that evidences a drama in his writing demonstrating the harmonic presence of the reversibility of opposites present since his first Poem poetry passing through the figures of Apollo. and Dionysus until he comes to the verses about Salazarism and the Revolução dos Cravos. Thus, the present article seeks to investigate the recurrences of the tragic in Andresian writing.
\end{abstract}

Keywords: Sophia de Mello Breyner Andresen, Greek Tragedy, Apollo, Dionysus, Contemporary Portuguese Poetry.

\section{Apesar das ruinas e da morte, \\ Onde sempre acabou cada ilusão, A força dos meus sonhos é tão forte, \\ Que de tudo renasce a exaltação E nunca as minhas mãos ficam vazias ${ }^{2}$. Sophia de Mello Breyner Andresen}

Sophia de Mello Breyner Andresen abre o seu primeiro livro - intitulado Poesia (1944) - com o poema que aqui nos serve de epígrafe. O poema nos remete a uma questão referente à dualidade: no início deparamo-nos com a imagem da "morte" e da "ruína", elementos de carga semântica negativa que impulsionam para um fim iminente. No caso, o sujeito poético vê as suas ilusões esvaírem-se e culminarem no fim último das coisas. Contudo, o sonho, o estado dionisíaco por excelência, é o caminho que proporciona uma força capaz de ultrapassar o estado

\footnotetext{
${ }^{1}$ Doutorando em Literatura Portuguesa pelo Programa de Pós-Graduação em Letras Vernáculas da Universidade Federal do Rio de Janeiro (UFRJ).

2 Para fins de citação dos poemas, levar em consideração a seguinte edição: ANDRESEN, Sophia de Mello Breyner. Obra poética. Lisboa: Assírio \&Alvim, 2015.
} 


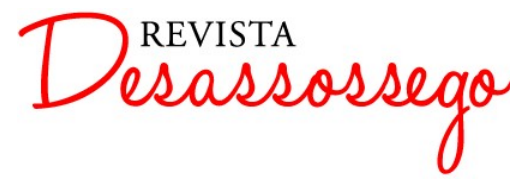

DESASSOSSEGO 21 | DEZ/2019 | ISSN 2175-3180

DOI: http://dx.doi.org/10.11606/issn.2175-3180.v11i21p61-74

limite ao ponto de resultar numa espécie de renascimento. O corpo do texto abriga o duplo domínio do vivo e do morto, em que a pulsão vital é designada pelo renascimento do que pode ser construído pelas "mãos" que nunca "ficam vazias", apesar de a figura nefanda da morte assombrar o sujeito. São as mãos o instrumento pelo qual o artista cria a sua obra, aquela que pode vir a vencer a morte, ultrapassar as ilusões perdidas e fincar na história a eternidade.

A metonímia da criação humana expressa pela imagem das mãos é retomada em outro poema, intitulado “Mãos", presente em Coral (1950). "Côncavas" e "longas de desejos", as mãos representam outra cena sob o signo da duplicidade. No primeiro verso da quintilha, a presença do verbo "ter" aponta para a ação de pegar alguma coisa que é reiterada pela posição "côncava" em que as mãos do sujeito se encontram na tentativa de circunscrever o objeto em sua superfície. Porém, o gesto não é suficiente para aprisionar e as mãos apenas “tocam” os objetos - fato que demonstra a impossibilidade de apreensão total do objeto por meio do instrumento de composição artística que se aproxima da "coisa" e manifesta a sua essência, transformandoa numa linguagem poética, artística, plasmada.

\author{
MÃOS \\ Côncavas de ter \\ Longas de desejo \\ Frescas de abandono \\ Consumidas de espanto \\ Inquietas de tocar e não prender.
}

O primeiro volume da poesia de Sophia inicia-se com o tema da morte, algo um tanto inquietante para uma poética que, aparentemente, celebra o seu oposto, seja a vida, a justiça, a harmonia e, por assim dizer, a perfeição das “coisas". Todavia, a figura da ceifadora de vidas impera nos primeiros versos andresianos e abre caminho para uma dualidade, um espaço de tensão entre vida e morte. Já o poema de Coral enfatiza a complexidade do gesto das mãos em querer se apoderar do objeto e, ao mesmo tempo, desejar apenas tocá-lo, uma duplicidade que não se resolve no interior do poema, mas que coexiste no espaço textual. $O$ aspecto ambíguo desenhado se estende por toda a obra, de modo que esta tensão dos contrários remonta ao "contínuo desenvolvimento da arte [que] está ligado à duplicidade do apolíneo e do dionisíaco" (NIETZSCHE, 1999, p.27). Mais adiante, em O nascimento da tragédia, Nietzsche afirma que

a seus dois deuses da arte, Apolo e Dionísio, vincula-se a nossa cognição de que no mundo helênico existe uma enorme contraposição, quanto a origens e objetivos, entre a arte do figurador plástico [Bildner], a apolínea, e arte nãofigurada [unbildlichen] da música, a de Dionísio: ambos os impulsos, tão diversos, caminham lado a lado, na maioria das vezes em discórdia aberta e incitando-se mutuamente a produções sempre novas, para perpetuar nelas a luta daquela contraposição sobre a qual a palavra comum "arte" lançava apenas aparentemente a ponte; até que, por fim, através de um miraculoso 
ato metafísico da "vontade" helênica, apareceram emparelhados um com o outro, e nesse emparelhamento tanto a obra de arte dionisíaca quanto a apolínea geraram a tragédia ática. (NIETZSCHE, 1999, p.27).

Não é novidade que Sophia de Mello Breyner possui uma adoração pelo mundo grego a tal ponto que o espaço helênico transborda por toda sua obra: da poesia ao ensaio em $O \mathrm{nu}$ na antiguidade clássica, tal aproximação revela o modo como a Grécia é percebida pela poeta: um espaço ideal, "como lugar feliz, no qual nasceram o pensamento racional, a democracia, a tragédia, a filosofia, e onde, no século de Péricles, se realizaria uma conjunção única de talentos: um milagre, em suma, ao qual inspira-se para reencontrar beleza e valores" (LANCIANI, 2013, p.102).

O interesse pela Antiguidade Clássica inclui o conhecimento dos dramas de Ésquilo, Sófocles e Eurípides. Inclusive, Sophia traduziu Medeia, cuja primeira edição pela Editorial Caminho data de 2006. Além do drama ático, a poeta também demonstra seus conhecimentos do drama shakespeariano, seja por aproximações/alusões em sua obra poética, seja pela tradução feita de Hamlet (1987, Porto, Lello \& Irmão Editores). A poesia andresiana possui reincidência de elementos do drama trágico que corroboram para uma poética da experiência do sujeito, em que a captura do real consiste na representação das emoções que o sujeito poético sente diante das cenas (re)construídas literariamente.

Ronaldes de Melo e Souza, em Ensaios de poética e hermenêutica (2010, p.59), nos diz que, “na poesia trágica dos gregos, os homens não se concebem divorciados dos deuses. Na verdade, a tragédia grega é fundamentalmente a luta entre os antigos e novos deuses". Mais adiante, em seu estudo, o autor conclui que "o drama trágico de Ésquilo, Sófocles e Eurípides é a representação da disputa do cosmos e do caos, da vida e da morte, da luz e da treva, enfim, da tensão harmônica dos contrários em luta em todos os aspectos da realidade cósmica" (SOUZA, 2010, p.62). Richard Zenith, em artigo intitulado "Uma Cruz em Creta: a salvação sophiana”, demonstra a co-existência do universo pagão e cristão na obra de Sophia:

A poesia de Sophia, para chegar à claridade e à limpidez que tanto preconiza, leva-nos por um confuso labirinto de alusões e associações, cruzando Creta com Delfos, a Grécia com Algarve, o reino de Deus com o reino do homem, o mundo da terra com o do mar, o cristianismo com o paganismo. É um universo de dualidades, mas estas não costumam estar nem inteiramente concordes nem em plena oposição. (ZENITH, 2013, p.210)

A poesia andresiana é uma escrita que busca a harmonia, a justeza da forma, a limpidez e a pureza, contudo essa mesma escrita não rejeita a sua contraparte e integra, dentro da sua estrutura, a desordem, a injustiça, a impureza, a treva e a morte. Os elementos que aparentemente se mostram excludentes encontram no corpo poético uma forma de 
coexistência, o que provoca a tão desejosa harmonia. Um dos exemplos que podemos retirar de sua obra são dois poemas que encontramos ainda em Poesia: "Evohé Bakkhos" e "Apolo Musageta”.

A presença dos dois textos, na obra inicial da poeta, reitera a nossa hipótese de que a escrita andresiana é construída sob a tensão dos contrários. Torna-se ainda mais sintomática a posição ou a ordem em que esses escritos nos são apresentados. O volume de Poesia divide-se em três sessões, sendo que os textos referidos se encontram na exata metade da primeira seção do livro e estão dispostos em sequência.

\section{EVOHÉ BAKKHOS}

Evohé deus que nos deste

A vida e o vinho

E nele os homens encontraram

O sabor do sol e da resina

E uma consciência múltipla e divina.

O poema é construído com apenas uma estrofe composta por cinco versos. Desde o título, que retoma o gesto cerimonial e litúrgico das bacantes que promovem os bacanais em homenagem a Baco (Dionísio), o poema consiste numa louvação à vida por meio do êxtase dionisíaco, no qual o indivíduo se encontra consigo mesmo, quando embevecido, de alma nua e liberta. O vinho, substância da vida e da imortalidade, também é concebido como símbolo do conhecimento e da iniciação, devido à embriaguez que provoca. É por meio do vinho que Baco embriaga os seus fiéis durante os seus rituais - a bebida podia tanto exercer um efeito exaltante quanto aterrorizante no sujeito. Senhor da vida e da morte, a duplicidade desta divindade é tensionada no quarto verso do poema por meio dos elementos "sol" e "resina". Segundo o Dicionário de símbolos de Chevalier e Gheerbrant (2009, p.836), o sol designa "se não o próprio deus", “uma manifestação da própria divindade”. A imagem solar é, por si só, uma figura contraditória, já que comumente ela é associada à iluminação, ao intelecto, à vida e a elementos de carga semântica positiva. Por causa disso, o "sol imortal nasce toda manhã e se põe toda noite no reino dos mortos; consequentemente pode levar com ele os homens e, ao se pôr, dar-lhes a morte; mas, ao mesmo tempo, pode guiar as almas pelas regiões infernais e trazêlas de volta à luz no dia seguinte" (CHEVALIER; GHEERBRANT, 2009, p.836). A "resina”, por sua vez, é "incorruptível", "símbolo da pureza e da imortalidade" (CHEVALIER; GHEERBRANT, 2009, p.778).

Baco é um deus que se diferencia dos demais deuses olímpicos, porque o seu ser não se distingue do não-ser e a sua vida não subsiste, senão porque a morte existe. Ele se configura 
como um agente da expansão vital e da contração mortal - dobrando-se e desdobrando-se, nascendo da sua própria morte, como bem elucidam os versos de Sophia em outro poema, desta vez em Dia do Mar: "Entre as árvores escuras e caladas/O céu vermelho arde,/E nascido da secreta cor da tarde/Dionysos passa na poeira das estradas" (ANDRESEN, 2014, p.45). Baco (ou Dionysos) congrega em si mesmo duas forças diametralmente opostas cuja potência da vivificação e "nadificação" não se sobrepõem, mas coexistem no mesmo ser que nasce e morre o tempo todo. O poema é construído sob a tensão dos contrários que, por coexistirem, e não se excluírem, permitem uma harmonia ontológica que culmina na criação do homem cuja “consciência" advém desta mesma ambivalência, tornando-o um ser contraditório.

A figura solar, como vimos, é evocada como uma imagem de potencialidade ambígua. No entanto, não nos podemos esquecer que Apolo é conhecido como o deus solar. Sophia, magistralmente, põe em sequência da sua louvação a Baco o louvor ao deus das musas, de modo que nos remete ao pensamento nietzschiano em que Apolo representa razão + paixão, símbolo da espiritualização e da ascensão humana) e Dionísio, o entusiasmo:

\author{
APOLO MUSAGETA \\ Eras o primeiro dia inteiro e puro \\ Banhando os horizontes de louvor. \\ Eras o espírito a falar em cada linha \\ Eras a madrugada em flor \\ Entre a brisa marinha \\ Eras uma vela bebendo o vento dos espaços \\ Eras o gesto luminoso de dois braços \\ Abertos sem limite. \\ Eras a pureza e a força do mar \\ Eras o conhecimento pelo amor. \\ Sonho e presença \\ De uma vida florindo \\ Possuída e suspensa. \\ Eras a medida suprema, o canôn eterno \\ Erguido puro, perfeito e harmonioso \\ No coração da vida e para além da vida \\ No coração dos ritmos secretos.
}

O poema abre-se com o verbo "ser" no pretérito imperfeito, que vai sendo repetido ao longo de todo o texto com o intuito de especificar a figura mitológica de Apolo. A figura do deus olímpico, segundo Píndaro, diz respeito ao deus que "faz penetrar nos corações o amor pela concórdia e o horror pela guerra civil” (CHEVALIER; GHEERBRANT, 2009, p.66).

O primeiro dístico do poema descreve o primeiro dia da criação: "inteiro e puro", aludindo a alguém ou a uma determinada circunstância semelhante a Apolo — deus da "medida 
suprema" e do "canôn eterno", "Apolo", apresentado como «condutor das musas», encontrase indissociável da natureza ("flor", "mar", "fogo", "vento"). O espaço natural, "puro", "perfeito" e "harmonioso" que é erguido pela palavra poética só é possível por meio "[d]o gesto luminoso de dois braços/Abertos sem limite". A terceira estrofe, por sua vez, harmoniza elementos contraditórios: "sonho e presença", "vida" e "suspensão".

O último verso da segunda estrofe apresenta uma contradição: "Eras o conhecimento pelo amor" - por um lado, o conhecimento aponta para o pragmatismo, para a racionalidade, que Aristóteles tanto defende em seus escritos, e, por outro lado, a presença sentimental do amor. Se o conhecimento é associado à experiência das emoções, então o verso citado vai contra o pensamento aristotélico que preza pela lógica. "Finalmente se verifica que a desconstrução nietzschiana da metafísica culmina no reconhecimento de que a verdade trágica dos poetas suplanta a verdade teórica dos filósofos" (SOUZA, 2010, p.53). A bipartição em matéria e espírito, defendida pela metafísica, impede o conhecimento total acerca do ser, pois exclui a subjetividade como forma de compreensão do mundo. Sophia vai contra a concepção platônica e aristotélica da verdade e advoga a favor do conhecimento proveniente das emoções, que culminam numa forma privilegiada de se aproximar do dinamismo contraditório da vida, afinal, nenhum ser é movido apenas pela razão e, neste sentido, a sua busca retrata as emoções como uma forma de conhecimento superior, tal qual ocorre com o drama trágico, como elucidado por Souza (2010):

$\mathrm{Na}$ Poética, Aristóteles não compreende nem interpreta as emoções fundamentais da tragédia grega, porque se concentra completamente na análise da estrutura lógica dos eventos (systasis ton pragmaton). Consonante com o ditame do raciocínio aristotélico, a mimese da ação não se refere somente a uma ação completa, mas também repleta de acontecimentos terríveis e lastimosos (phoberon kai eleeinon). As emoções terríveis e lastimosas decorrem da concatenação lógica das ações. Ações, e não emoções, constituem o objeto privilegiado pela poética aristotélica. A estrutura lógica dos eventos ou das ações tem por função suscitar emoções terríveis e lastimosas. As emoções que determinam ontologicamente o destino dos personagens trágicos são neutralizadas e substituídas pelas supostas emoções que o drama provoca nos espectadores. Logicamente concebido, o trágico resulta de um erro cometido pelo herói, que desencadeia acontecimentos desastrosos, que culminam na catástrofe. No entanto, o trágico poetizado na tragédia grega não resulta do erro decorrente da ignorância passível de correção pelo autorreconhecimento (anagnorisis), mas da errância ontológica do homem em luta com a potência do destino. As forças formidáveis, divinas e demoníacas, que arrebatam e subjugam os homens ou que irrompem tempestuosamente da profundidade recôndita do ser humano, é que constituem e determinam o sentido do trágico na dramaturgia de Ésquilo, Sófocles e Eurípides (SOUZA, 2017, p.24).

O espaço geográfico em que os poemas "Evohé Bakkhos" e "Apolo Musageta” se encontram é bastante sintomático. A presença do deus do duplo domínio da vida e da morte 
aliada à do deus solar, justo e puro, promove a harmonia que tanto a escrita andresiana persegue. Um não pode existir sem a presença do outro e, neste sentido, obtemos uma alusão fugidia a ambos os deuses no poema "Sinal de ti":

\section{É Dyonysos que passa nas estradas \\ E Apolo quem floresce nas manhãs}

Concordamos com Helena Carvalhão Buescu quando nos diz que "a procura (ou a sabedoria) da unidade implica também o saber da divisão, numa espécie de complementariedade indissociável que implica não recusar o que divide, porque por ele se pode saber o que une" (2005, p.65). A própria Sophia possui consciência da dicotomia entre o apolíneo e o dionisíaco presentes em sua obra, visto que a autora, ao ser confrontada com esta questão, afirma numa entrevista concedida a António Guerreiro e publicada no Expresso (15-71990 s/p.):

Tive sempre a consciência de que a arte era filha de Dionísio e de Apolo. O que acontece é que tudo o que é dionisíaco na literatura é geralmente tratado de um modo confessional. Penso que toda a arte vive de discórdia e de contradição, [...] da tensão entre forças e elementos opostos. Um dia, o poeta francês Pierre Emmanuel escreveu-me a seguinte dedicatória num dos seus livros: "Para a Sophia em quem vivem a sabedoria de Orfeu e a loucura das Ménades".

O tema da harmonia dos contrários faz com que a poesia de Sophia tenha filiação no drama trágico, entretanto, a concepção do drama da poeta não compactua com o conceito aristotélico de tragédia, uma vez que a Poética de Aristóteles tem por propósito a clarificação da origem, da natureza e da função da tragédia grega, tal como o pensador a caracteriza como:

imitação de uma ação de caráter elevado, completa e de certa extensão, em linguagem ornamentada e com várias espécies de ornamentos distribuídas pelas diversas partes do [drama], [imitação que se efetua] não por narrativa, mas mediante atores, e que, suscitando o terror e a piedade, tem por efeito a purificação dessas emoções (ARISTÓTELES, 1973, p.447).

Partindo daqueles que foram contra a doutrinação do pensamento filosófico de Aristóteles, mas que foram ignorados, Ronaldes de Melo e Souza retorna a Hölderlin e a Nietzsche, dentre outros filósofos como Walter F. Otto, Karl Reinchardt, Wolfgang Schadewaldt e, até mesmo, Heidegger, para nos dizer que o drama trágico não compactua com a noção aristotélica de enredo lógico, isto porque "a tragédia grega se concentra na compreensão e interpretação das emoções, e não na representação de ações. Não são ações que provocam emoções, mas as emoções é que produzem acontecimentos frequentemente portentosos" (SOUZA, 2017, p.25).

Seguindo o pensamento de Souza, a tragédia grega se configura como um drama estático por excelência, uma vez que “os personagens trágicos não são agentes, porque mais sofrem do 
que agem" (SOUZA, 2017, p.25). Nesse sentido, a tragédia grega passa da mimesis para a sintesis, priorizando as reflexões sobre as emoções experienciadas pelas personagens trágicas em detrimento das ações que se encontram em segundo plano.

Em Édipo Rei, por exemplo, o drama trágico se abre com os acontecimentos já ocorridos, desta forma o que vemos é a repercussão dos eventos na vida das personagens e como eles influenciam as suas experiências. A peça de Sófocles inicia-se com Édipo a buscar a resposta para a maldição que recaiu sobre Tebas, sendo que a própria personagem desconhece que ele é a origem dos tormentos. As ações já haviam ocorrido, ou seja, a previsão do oráculo fora concretizada: a personagem já havia cometido o assassinato do próprio pai e desposado a própria mãe, sem ao menos ter conhecimento de quem eram essas figuras. $\mathrm{O}$ drama trágico de Sófocles reside numa ironia trágica: afinal, o que adianta a Édipo saber desvendar o enigma da esfinge sendo aquele que sabe tudo acerca de tudo, se não sabe quem é a si próprio?

Em Sófocles, a tragédia reside num drama ontológico que consiste na descoberta do que é o homem e o que é a natureza humana. O poeta concebe o homem como um ser complexo que não possuí forma definida. Antes de tudo, o homem é um ser contraditório que possui emoções: éleos (compaixão) e phobos (repulsão). É, portanto, o ser mais horrível e mais admirável (tó deinotaton), aquele que abriga em si mesmo forças antagônicas, mas que coexistem num mesmo espaço de forma harmônica, pois uma não se sobrepõe à outra.

A poesia andresiana afilia-se à concepção trágica do drama e afasta-se da concepção mimética da realidade. Uma das engrenagens que faz girar a máquina poética de Sophia reside na sua constante «perseguição do real», como bem elucida Eduardo Prado Coelho quando nos diz que o fazer poético da autora consiste em "procurar apreender as coisas, delimitando-as, vincando os seus contornos, assinalando os seus limites e o seu recorte no horizonte" (1972, p.225). Diz ele: "quanto mais o real é abordado na sua particularidade, maior é a necessidade de encontrar a dimensão universal que o articula. Quer dizer que não poderemos ver as coisas sem nelas ver o seu «fogo devorador»" (COELHO, 1972, p.226, grifos do autor).

O trabalho poético de apreensão do real consiste não na captura do objeto, mas sim na tentativa de capturar e representar a experiência que o sujeito poético possui diante deste mesmo objeto. Vejamos, por exemplo o poema "A casa":

\section{A CASA}

A casa que eu amei foi destroçada

A morte caminha no sossego do jardim

A vida sussurrada na folhagem

Subitamente quebrou-se não é minha 
O poema acima diz respeito a um dos espaços a que a poesia de Sophia mais se dedica: a casa. Esse ambiente é construído como um espaço de abrigo, da intimidade, é o "não-eu que protege o eu" (BACHELARD, 2008, p.24); consiste na segunda morada do sujeito no mundo, e sem o espaço da casa o homem se tornaria um ser disperso. O espaço descrito no poema abriga, no seu interior, a figura nefanda da morte, que novamente é retomada pelos versos da poeta. Entre a experiência amorosa reside a ruína, algo que o sujeito poético vê destroçado, porque "a morte caminha no sossego do jardim" e este lugar, por sua vez, pode remeter simbolicamente aos jardins de Roma que designam as "lembranças de um paraíso perdido" (CHEVALIER; GHEERBRANT, 2009, p.512). No caso do poema, a casa mostra-se como um lugar em que a morte existe, caminha, transita entre o natural e, por que não o humano? Afinal, não nos podemos esquecer de que, em tese, o jardim representa o triunfo do homem sobre a natureza com o intuito de domesticá-la.

A casa, por sua vez, no espaço poético andresiano, abriga não só a morte (apresentada em trânsito) como também "a vida sussurrada na folhagem” do jardim. É um espaço ambivalente que tanto possui a pulsão vital como a pulsão da "nadificação". A casa destroçada, por sua vez, pode ser vista como uma morada perdida ou como a ruína de uma memória.

A casa, como o fogo, como a água, nos permitirá evocar, na sequência de nossa obra, luzes fugidias de devaneio que iluminam a síntese do imemorial com a lembrança. Nessa região longínqua, memória e imaginação não se deixam dissociar. Ambas trabalham para o seu aprofundamento mútuo. Ambas constituem, na ordem dos valores, uma união da lembrança com a imagem. (BACHELARD, 2008, p.25)

O verbo «aman», presente no poema acima referido, conjugado no pretérito perfeito, nos sugere a imagem de um sujeito poético a relembrar a morada. Este gesto de memória traz para o corpo poético o objeto "casa" e o transforma segundo a experiência desse eu diante do espaço recriado. A percepção do real advém, portanto, da experiência passada, do gesto amoroso que ainda se prolonga no texto, por ainda ser um lugar possível de revisitação.

O poema «A casa» é publicado pela primeira vez no livro Dual, em 1972, abrindo o volume. Curioso é o fato de que o primeiro poema traga em sua estrutura a temática da morte, tal qual é em Poesia. Mais inquietante ainda é a aproximação que podemos fazer com a biografia da autora, na medida em que este é o primeiro livro publicado após a morte do irmão e da mãe, como nos aponta a carta escrita a Jorge de Sena em 31 de dezembro de 1967:

O meu irmão João (o arquitecto) morreu subitamente com ataque do coração no dia 25 de Junho. (...) Mas em meados de Setembro tive de partir para o Porto onde a minha Mãe foi operada aos intestinos, a um tumor maligno. (...) Mas por roda de 10 de Novembro a minha Mãe piorou de repente e morreu no dia 17. (ANDRESEN; SENA, 2010, p.105). 
Não estamos afirmando que o espaço poético é destinado à transcrição de biografismos; contudo, não se pode desprezar a experiência do sujeito diante da imagem de uma casa cuja presença da morte ronda o jardim. Nesse sentido, o próprio texto nos permite a comparação entre aquilo que a palavra poética descreve e aquilo que o sujeito civil vivenciou, sem que a qualidade artística se perca mediante o contato biográfico.

A experiência como forma de conhecimento é uma constante da poética andresiana, que se associa, particularmente, com a concepção do drama trágico. As questões que movem cada poeta trágico dizem respeito às experiências vivenciadas pelos personagens trágicos cujas emoções são o tema principal sobre o qual se debruça cada peça dramática. A tragédia grega visa à interpretação das emoções suscitadas pelas ações, sendo assim, vemos, em Ésquilo, a questão do sofrimento e da redenção; em Sófocles, a questão da dor; e, em Eurípides, o conflito entre razão e paixão.

O nome das coisas, livro publicado em 1977, é o primeiro livro de poesia de Sophia que procede à Revolução dos Cravos. Grande parte dos seus poemas reflete o sentimento do sujeito diante da possibilidade do término do período de opressão, silenciamento, proveniente do poder totalitário instituído por Salazar. Por isso, inscrevem-se no espaço textual simultaneamente o desejo utópico de liberdade, harmonia e renascimento advindo da Revolução e, por fim, a perda da ilusão do sujeito diante da errância que se mostra no pós-25 de Abril.

O poema intitulado "Guerra ou Lisboa 72" refere-se à guerra em África, para onde o “jovem forte" parte "vivo" e volta "bem grave e calado" "com morte no passaporte". A poeta transcreve de forma precisa a situação daqueles que foram enviados para uma guerra e voltam com a experiência da dor, do trauma ou mortos. A indiferença diante daqueles que lutaram numa batalha sem vencedores, mas vencidos pela força do Estado, é descrita de forma precisa pelos versos: "Sua morte nos jornais/Surgiu em letra pequena". E, ao final, o eu poético faz um apelo: "É preciso que o país/Tenha a consciência serena".

\footnotetext{
GUERRA OU LISBOA 72

Partiu vivo jovem forte

Voltou bem grave e calado

Com morte no passaporte

Sua morte nos jornais

Surgiu em letra pequena

É preciso que o país

Tenha a consciência serena
} 
O tema do salazarismo perpassa toda a obra da autora, podendo ser percebido em poemas como "Carta aos amigos mortos", "Pátria", "Exílio", "O velho abutre", ambos de Livro sexto; "Esta gente", de Geografia; "Caxias 68", de Dual; "Exílio", de Dia do Mar, dentre tantos outros que direta ou indiretamente retratam a situação de Portugal imerso no poder nefando da ditatura. Porém, é em $O$ nome das coisas que o desejo de liberdade toma forma poética e surge:

\section{COMO O RUMOR}

Como o rumor do mar dentro de um búzio

O divino sussurra no universo

Algo emerge: primordial projecto

O “primordial projecto” chega na madrugada do dia 25 de Abril de 1974. A Revolução dos Cravos instaura, na pátria portuguesa, a possibilidade de renovação e o gosto da liberdade:

25 DE ABRIL

Esta é a madrugada que eu esperava

O dia inicial inteiro e limpo

Onde emergimos da noite e do silêncio

E livres habitamos a substância do tempo

Para Sophia, o momento da Revolução é um tempo de reescritura, como "página em branco", onde o poema "emerge" e onde a vida principia. Este momento consiste num ato de descobrimento, pois designa um estado de experiência, e a poeta nos diz em outro poema:

\section{REVOLUÇÃO - DESCOBRIMENTO \\ Revolução isto é: descobrimento \\ Mundo recomeçado a partir da praia pura \\ Como poema a partir da página em branco \\ - Kartharsis emergir verdade exposta \\ Tempo terrestre a perguntar seu rosto}

Sophia define o termo "Revolução" no primeiro verso do poema: "descobrimento". O período histórico em questão é insistentemente associado à ideia de pureza, de harmonia, liberdade, enfim, é um instante construído a partir de semas que proporcionam uma clareza ao caos anteriormente instituído em Portugal. O que nos chama a atenção, neste poema, é o fato de que a Revolução não é algo passivo a ser observado pelo sujeito, mas uma experiência que deve ser vivenciada, descoberta, de forma ativa. A própria pureza do estado de espírito que se instaura no sujeito é um momento que faz nascer o desejo de criação a partir da página em branco onde o poema emerge. A palavra poética funciona como "Kartharsis", não no sentido 


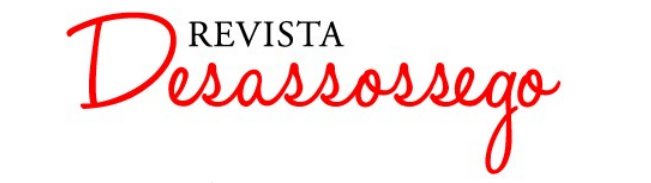

DESASSOSSEGO 21 | DEZ/2019 | ISSN 2175-3180

DOI: http://dx.doi.org/10.11606/issn.2175-3180.v11i21p61-74

aristotélico $^{3}$, mas na concepção de que

as emoções efetivamente trágicas, que são assumidas e sofridas pelos personagens da tragédia grega, transformam radicalmente a existência dos sofredores. Não podem, portanto, ser confundidas com as emoções psicológicas dos espectadores, que são transitórias, fugazes e destituídas de verdadeira aprendizagem. As emoções genuinamente trágicas são ontológicas, e não psicológicas" (SOUZA, 2017, p.27-28).

É preciso vivenciar a Revolução para que se possa descobrir a liberdade, a vida pura e inteira. Só o sujeito que experiencia o instante revolucionário é capaz de "transformar radicalmente" a sua vida. Os poemas de Sophia sobre a questão salazarista e pós-ditadura configuram uma tentativa de captar o instante, aprisionar o real por meio da experiência do sujeito poético e transformar aquilo que se vivencia em experiência que, por fim, torna-se conhecimento. Jorge Fernandes da Silveira, em artigo sobre o retorno do épico, nos comunica o gesto de solidariedade que existe entre os poemas num tempo de interdição:

\begin{abstract}
a interlocução entre versos [pode] ser lida como a construção de uma linguagem capaz de, em correspondências, dizer como em estado de censura, de proibição do livre trânsito da palavra, a poesia aprende a dizer, soletra, diz, e ensina a dizer, escreve o sentido de falar de liberdade em tempos de opressão, de fazer poemas como se fossem «notícias do bloqueio» por meio da troca de versos entre poetas ao mesmo tempo solitários e solidários com e por imagens (SILVEIRA, 2010, p.34)
\end{abstract}

Sophia de Mello Breyner Andresen possui exatamente esta postura solidária e solitária em sua obra poética. Ocorre que as palavras ditas e entreditas — e, por que não, interditas? — são plasmadas a partir da sua percepção do real, da sua visão enquanto sujeito civil que traduz, na folha em branco, suas experiências, transformando-as em conhecimento, como nos aponta Eduardo do Prado Coelho:

Se ser poeta é tentar estabelecer uma relação justa, exacta, digna, com o mundo, assinalando os contornos, fixando as cores adequadas, a verdade é que não podemos apenas conceber o mundo como presença a referências. As coisas que nos rodeiam estão trabalhadas pela ausência, ausência que em cada instante as expõe na claridade do sol para logo as dissimular no labirinto da noite. (COELHO, 1972, p.227, grifos do autor)

\footnotetext{
${ }^{3}$ Ronaldes de Melo e Souza (2017, p 27) exemplifica o sentido da catarse aristotélica, vejamos: "Na famigerada definição aristotélica, a tragédia grega tem por função suscitar as emoções do lamento e do terror (eleos kai phobos) e realizar a catarse dessas emoções. A suscitação e a catarse se referem aos espectadores. A função do drama ático consiste em produzir uma catarse (peranein katharsin) nos receptores e auditores tensionados entre duas emoções simétricas e opostas, uma de atração compassiva pelo sofrimento lastimável do herói (eleos), outra de repulsa e aversão pelos atos nefandos cometidos consciente ou inconscientemente pelo protagonista (phobos). As emoções que subjugam os espectadores são suscitadas pelos eventos terríveis e lastimosos, que se sucedem logicamente regidos pela necessidade e verossimilhança. A catarse das emoções se realiza quando, no desenredo do drama, os espectadores se libertam do peso doloroso do enredo trágico e experimentam o prazer e a alegria do retorno ao mundo familiar da vida quotidiana. As emoções experimentadas duram algumas horas, mas não perduram, porque não transformam o modo de ser e existir dos espectadores".
} 


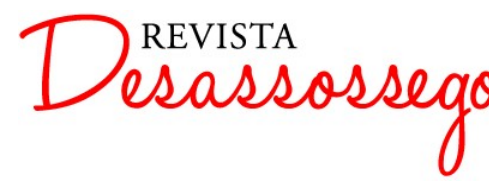

DESASSOSSEGO 21 | DEZ/2019 | ISSN 2175-3180

DOI: http://dx.doi.org/10.11606/issn.2175-3180.v11i21p61-74

O espaço puro da página em branco é o espaço onde Sophia busca transcrever a sua realidade diante de um tempo que retira do sujeito a liberdade. A palavra poética surge como dicção capaz de materializar o desejo, o pensamento e as palavras de alguém que procura comunicar-se com o mundo. O poema, portanto, funciona como uma "certa forma de atestação existencial de valores estéticos que são, intrinsecamente, também éticos" (BUESCU, 2005, p.47).

O gesto de criação desempenhado pelas "mãos" da poeta reside na forma trágica oriunda do drama ático que preza pela harmonia, sem que haja a exclusão das forças opostas que geram um embate sem vitória. "O trágico é a suprema harmonia do ser (die stärkste Harmonie des Seins), porque lhe pertence a dissonância como a mais profunda forma de consonância (die Dissonanz als die tiefere For der Konsonanz (Pigenot, 1923)" (SOUZA, 2010, p.71). Nesse sentido, a poesia de Sophia é formada pelo caos e pelo cosmos, pela luz e pelas trevas, pela vida e pela morte, pelo apolíneo e pelo dionisíaco em seu processo de revisitação e de transmutação da antiguidade clássica.

\section{BIBLIOGRAFIA:}

ANDRESEN, Sophia de Mello Breyner. Obra poética. Lisboa: Assírio \& Alvim, 2015.

ANDRESEN, Sophia de Mello Breyner; SENA, Jorge. Correspondências (1959-1978). Lisboa: Guerra e Paz, 2010.

ARISTÓTELES. Poética, In: Os pensadores. Vol. IV. São Paulo: Abril Cultural, 1973, p.237-270. BACHELARD, Gaston. A poética do espaço. São Paulo: Martins Fontes, 2008.

BUESCU, Helena Carvalhão. "Sophia no país das maravilhas". In: Cristalizações: fronteiras da modernidade. Lisboa: Relógio D’Água Editores. 2005.

CHEVALIER, Jean; GHEERBRANT, Alain. Dicionário de símbolos, mitos, sonhos, costumes, gestos, formas, figuras, cores, números. São Paulo: José Olympio, 2009.

COELHO, Eduardo Prado. O real, a aliança e o excesso na poesia de Sophia de Mello Breyner Andresen. In: A palavra sobre a palavra. Porto: Portucalense Editora, 1972. p.225-232.

GUERREIRO, António. "Entrevista a Sophia de Mello Breyner Andresen”, Expresso, 15-7-90. LANCIANI, Giulia. Sophia de Mello Breyner Andresen: o labirinto da palavra. In: ANDRESEN, Sophia de Mello Breyner. Actas do Colóquio Internacional. (Org.) Maria Andresen de Souza Tavares e Centro Nacional de Cultura. Porto: Porto Editora, 2013, p.98-104.

NIETZSCHE, Friedrich. O nascimento da tragédia ou helenismo e pessimismo. São Paulo: Companhia das Letras, 1999.

SILVEIRA, Jorge Fernandes da. O retorno do épico: a nau e a nave. In. Metamorfoses. V. 10.2, 


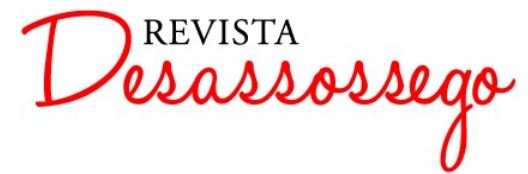

Caminho, Maio de 2010, p.33-41.

SOUZA, Ronaldes de Melo e. Ensaios de poética e hermenêutica. Rio de Janeiro: Oficina de Raquel, 2010.

SOUZA, Ronaldes de Melo e. Fenomenologia das emoçẽes na tragédia grega. Rio de Janeiro: 7Letras, 2017.

ZENITH, Richard. Uma Cruz em Creta: a salvação sophiana. In: ANDRESEN, Sophia de Mello Breyner. Actas do Colóquio Internacional. (Org.) Maria Andresen de Souza Tavares e Centro Nacional de Cultura. Porto: Porto Editora, 2013, p.207-2014. 